\title{
Luz del Fuego: celebridade, gênero e moralidade no Brasil
}

\section{Everardo Rocha}

Pontifícia Universidade Católica do Rio de Janeiro, Rio de Janeiro, Brasil

\section{Lígia Lana}

Pontifícia Universidade Católica do Rio de Janeiro, Rio de Janeiro, Brasil

\section{Resumo}

Este artigo investiga a trajetória midiática de Luz del Fuego em revistas e jornais brasileiros de 1930 a 1970. Quatro temas marcantes foram identificados: carnaval, violência, censura e política. A pesquisa examina, em torno desses temas, a relação entre celebridade, gênero e cultura, observando os modos como Luz del Fuego se posicionou como mulher famosa. O trabalho indica que Luz del Fuego soube ser um sucesso de escândalo, tendo planejado uma carreira, antes de mais nada, midiática. As conclusões mostram que, ao promover distúrbios morais no espaço público, ela participou, de maneira ambígua, das transformações dos papéis sociais de mulheres e homens entre 1950 e 1970.

\section{Palavras-chave}

Celebridade. Gênero e mídia. História da mídia.

\section{Introdução}

Nos anos 1950, o Brasil - especialmente a cidade do Rio de Janeiro - acompanhou a trajetória de uma mulher singular. Com vestes sumárias ou completamente nua, enrolada em cobras e serpentes de cerca de dois metros de comprimento, ela apresentava, nos principais teatros do país, shows de dança embalados pelas contrações, ondulações e deslizamentos dos animais em seu corpo. Naquela época, provavelmente, bastaria fazer menção à dançarina da cobra ou ao nome Luz del Fuego para que qualquer pessoa a reconhecesse: tendo alcançado o estrelato no teatro de revista, ela foi, assim como suas contemporâneas Elvira Pagã e Virginia Lane, uma vedete brasileira, noticiada de maneira maciça pela mídia. Recebeu o título de rainha do carnaval carioca, participou de bailes no Teatro Municipal, excursionou com seus espetáculos, teve sua vida privada esmiuçada por revistas e colunas de fofoca. 
Entretanto, algumas particularidades tornam Luz del Fuego uma celebridade muito especial para a reflexão sobre o estatuto da fama de mulheres no Brasil. Dora Vivacqua, seu nome de batismo, escreveu dois livros, propôs a criação de um partido político, planejou uma campanha para o cargo de deputada federal, fundou o movimento naturista no Brasil, construiu, em uma ilha inóspita da Baía de Guanabara cedida pelo governo federal, um clube dedicado ao naturismo e defendeu a causa animal. Luz del Fuego representou, entre o final da década de 1940 até seu assassinato, em 1967, uma figura muito relevante na vida cultural, política e social brasileira. Ela foi tema de incontáveis matérias, reportagens, artigos e fotografias. Seu nome aparecia em enigmas de palavras-cruzadas, era destaque de capa em jornais diários e foi apresentado na revista Life. A mídia anunciava cotidianamente suas opiniões a respeito dos mais diferentes assuntos: justiça e polícia, valores e costumes femininos, saúde humana e natureza e, até mesmo, o que Luz del Fuego achava do governo Getúlio Vargas e da campanha de Plínio Salgado à presidência.

Com a urbanização, a industrialização e o otimismo com a modernização do país, o Brasil experimentava, na década de 1950, os "anos dourados". A consolidação da vida urbana trouxe o aumento da oferta de trabalho, cursos universitários, informação, lazer e consumo para homens e mulheres. O período permanecia, contudo, como uma era de "modelos rígidos" (PINSKY, 2012), em que as distinções entre os papéis de femininos e masculinos continuavam explícitas. "Na família-modelo dessa época, os homens tinham autoridade e poder sobre as mulheres e eram os responsáveis pelo sustento da esposa e dos filhos. A mulher ideal era definida a partir dos papéis femininos tradicionais - ocupações domésticas e o cuidado dos filhos e do marido" (PINSKY, 2012, p. 608). Havia, assim, uma latente ambiguidade entre a convocação da mulher ao trabalho, aos estudos, ao lazer e ao consumo e, ao mesmo tempo, à manutenção de valores e comportamentos tradicionais da vida doméstica. As mulheres viviam um duplo enredamento: depois de terem sido incentivadas a trabalhar e a se sentirem autônomas no período da guerra, elas passavam a ser impulsionadas de volta ao lar, algo que Betty Friedan (1971) identificou muito bem no clássico Mística Feminina.

Os anos 1950 são um período muito rico para a compreensão da gênese da mulher do século XXI, pois explicitam disputas entre o conservadorismo do modelo da rainha do lar e a necessidade da criação de uma mulher emancipada para o consumo e o trabalho, questões que ocupam ainda hoje o debate público. Esses limites entre público e privado são subjetivos, 
discursivos e sensíveis, constantemente sujeitos à disputa e raramente controlados de maneira calculada e racional.

As transformações dos papéis da mulher na vida social foram muito marcantes nos anos 1950, e a mídia participou ativamente desse processo. O cinema e o rádio tornaram-se mais populares. Filmes, atrações musicais, revistas e celebridades passaram a ocupar o imaginário popular de maneira intensa. Atrizes, cantoras e artistas colocam mulheres em evidência no espaço público da mídia; admiradas, elas passam a promover modelos de comportamento, coabitando um lugar antes reservado aos homens (PERROT, 1998). Secularmente, o espaço público foi masculino: os heróis de guerra, os líderes políticos e religiosos, os cientistas e os artistas eram apenas os homens. ${ }^{1} \mathrm{O}$ período de aparecimento das celebridades na mídia, associado à ascensão das estrelas de cinema (MORIN, 1989), marca também essa possibilidade de novos lugares públicos para as mulheres - que, desde o século XIX, haviam começado a transitar mais livremente nas cidades, como burguesas nos centros comerciais, vendedoras ambulantes e lavadeiras nas ruas. ${ }^{2}$
A problematização da relação entre celebridades e questões de gênero indica a relevância dessas novas figuras públicas - subordinadas às tecnologias da mídia - para avaliação dos papéis de homens e mulheres na vida social. Nos anos 1950, produtos midiáticos e artistas que pudessem colocar em dúvida o destino natural das moças de família eram colocados sob suspeita. "Alguns conservadores chegavam a criticar o cinema americano por trazer para o Brasil más influências, mostrando como normais hábitos condenáveis, tais como mocinhas ousadas e cheias de iniciativa que não respeitam os mais velhos" (PINSKY, 2012, p. 610).

É provável que os maiores fãs dos espetáculos de Luz del Fuego eram homens, o que, a princípio, não representaria riscos para a corrupção das moças de família - bastava qualificá-la como mais uma "doidivana" do teatro de revista, que não seria modelo para as mulheres brasileiras. No teatro de revista, vedetes eram protagonistas de um universo irreverente, marcado pela transgressão. Os espetáculos eram satíricos e recorriam à sensualidade, articulando debates sociais, questões culturais e políticas (PAIVA, 1991). Luz del Fuego estrelou os momentos finais do teatro

10 termo "homens públicos" remete aos sujeitos ilustres das cidades. Em contraste, o termo "mulheres públicas" alude às prostitutas, expressando "[...] a vergonha, a parte escondida, dissimulada, noturna, um vil objeto." (PERROT, 1998, p. 7).

2 Transformações bastante estudadas no campo da história (DUBY; FRAISSE; PERROT, 1991; LANDES, 1988; PERROT, 1998). 
de revista no Brasil. As provocações do teatro de revista revelavam as contradições de um país que se urbanizava, mas, ao mesmo tempo, mantinha uma organização social conservadora e oligárquica.

Além disso, as apresentações de Luz del Fuego, ao contrário do cinema hollywoodiano ou das novelas do rádio, não traziam narrativas melodramáticas estruturadas com happyend, típicas na normatização do comportamento feminino. Nos palcos de Luz del Fuego, apresentavam-se espetáculos cômicos com travestis, bailarinos, humoristas e cobras, muitas cobras - em um show no Teatro da República, em maio de 1954, o Correio da Manhã anunciou que Luz del Fuego se apresentaria com 110 serpentes. (FLAGRANTES, 1954, p. 2).

Luz del Fuego, nome artístico que ela mesma escolheu, menção à marca de um batom argentino, perturbava o imaginário de brasileiros e brasileiras não apenas porque ia além do papel esperado de uma artista de teatro, mas, sim, porque era uma vedete nascida em berço de ouro, que frustrou o esperado e natural projeto de se tornar uma boa moça de família. José e Margarida Vivacqua, avós de Dora, eram italianos que chegaram ao Espírito Santo no final do século XIX, trazendo economias que renderam a construção de um empório e a compra de animais de transporte. Com a cessão de terras pelo governo, a família passou também a criar gado leiteiro e a plantar gêneros de primeira necessidade, construindo um próspero negócio, que tornou a família proeminente na região (AGOSTINHO; PAULA; BRANDÃO, 1994).

Nascida em Cachoeiro do Itapemirim, em 21 de fevereiro de 1917, Dora era uma das caçulas dos 14 filhos, sete homens e sete mulheres, de Antônio e Etelvina Vivacqua. Seus irmãos foram pessoas influentes na vida política e cultural do Rio de Janeiro e de Belo Horizonte. Na capital mineira, onde, ainda criança, Dora viveu por alguns anos, a casa de sua família, o Salão Vivacqua, imponente casarão na esquina das ruas Gonçalves Dias e Sergipe, recebia saraus mensais com a presença dos escritores Carlos Drummond de Andrade - que foi namorado de sua irmã Mariquinhas - Pedro Nava e Milton Campos, além de Menotti Del Pichia, Guilherme de Almeida e Aníbal Machado. No Rio de Janeiro, por algum tempo, morou sob a tutela do irmão Attilio, político brasileiro que ocupou diversos cargos na administração pública e foi eleito senador em 1946 (AgOSTINHO; PAULA; BRANDÃO, 1994).

Segundo a biografia Luz del Fuego, a bailarina do povo, Dora teria crescido como uma menina insolente. "Respondia aos professores e durante os castigos fazia caricaturas e deboches deles. Fora expulsa das aulas de religião 
porque falara que as missas domingueiras não passavam de exibição dos grã-finos, fingindo sentimentos que não tinham." (AGOSTINHO; PAULA; BRANDÃo, 1994, p. 85). Aos seis anos, encantou-se com o serpentário do Instituto Ezequiel Dias, que ficava próximo à sua casa. "Desde que o descobriu, logo após a mudança para Belo Horizonte, Dora não quer saber de outro passeio. [...] Quando o funcionário de avental branco recolhe uma jararaca ou uma cascavel na ponta de uma vara para a retirada do veneno, fica excitada, grita para que se aproxime." (p. 77-78).

Mais tarde, morando no Rio de Janeiro na casa de Attilio, ela foi mandada de volta para Minas Gerais, em 1936. O irmão não tolerava mais a rotina de Dora na cidade - aos 19 anos, ela não respeitava regras ou horários impostos por Attilio. Dora foi viver com a irmã Angélica, em uma chácara. Pouco tempo depois, Carlos, marido de Angélica, teria abusado sexualmente de Dora, fato dramaticamente presenciado pela esposa. Para preservar o casamento, Angélica "[...] mesmo ciente da culpa do marido, achara prudente abafar o escândalo internando Dora num manicômio." (AgOSTINHO; PAUla; BRANDÃO, 1994, p. 113). Dora permaneceu internada por dois meses no Hospital Raul Soares, em Belo Horizonte, onde passou por tratamentos psiquiátricos como banhos frios, recolhimento em solitária e sedativos. Antes de completar 21 anos, Dora foi internada mais uma vez em um hospital psiquiátrico, a Casa de Saúde Dr. Eiras. As internações de Dora, narradas sem muitos detalhes em sua biografia, podem ser vistas como prenúncio de momentos que, como veremos adiante, iriam ocorrer, em que foi ela acusada publicamente de insanidade mental e caracterizada como pessoa insensata. As internações compulsórias parecem ser formas de corrigir ou "curar" desvios comportamentais - que, de acordo com nossa análise, não parecem estar associados a transtornos mentais, mas, sim, à uma figura complexa, caracterizada pela provocação, pela inteligência e pela crítica.

Depois da segunda internação, ela morou alguns meses em Campos, no estado do Rio de Janeiro, voltou a Cachoeiro do Itapemirim, até fugir para fixar residência definitiva na cidade do Rio de Janeiro. Seu primeiro endereço próprio foi o internato para mulheres no Colégio Imaculada Conceição, em Botafogo, em 1937.

De acordo com pesquisa na Hemeroteca Digital da Biblioteca Nacional, as primeiras menções a Dora Vivacqua em jornais e revistas no país datam dos anos 1930. Naquele momento, há apenas o simples registro de seu nome: como "moça da sociedade", ela compareceu a uma festa no Rio de Janeiro; inscreveu-se e foi aprovada nas provas para 
conduzir automóveis; foi listada, junto com outros integrantes da família, como titular de bens monetários; participou da prova de natação que inaugurou a piscina do Clube Atlético Mineiro, em Belo Horizonte. Em 1939, pela primeira vez, Dora Vivacqua surgiu de maneira mais extensa: ainda sem assinar Luz del Fuego, ela era a "aviadora Dora Vivacqua", uma das poucas mulheres que possuíam brevê no país.

Em meados dos anos 1940, entre 1944 e 1945, o nome Luz del Fuego aparece pela primeira vez na pesquisa na Hemeroteca Digital. Ao lado de Aymond, no Teatro Recreio, Luz del Fuego estava em cartaz com o show "Tudo é Brasil". Tratava-se de anúncios pagos, divulgados nos jornais de maior circulação daquele período: Diário Carioca, Jornal do Brasil e Diário da Noite. A partir desse período, encontram-se milhares de recorrências do termo Luz del Fuego; Dora Vivacqua torna-se complemento de seu nome principal. Nesta análise, apresentamos uma reflexão sobre o material encontrado a partir desse período até 1970.

A busca por informações de Luz del Fuego nos periódicos brasileiros indicou a transformação de um nome inicialmente veiculado em anúncios pagos do teatro de revista
- quer dizer, associado à propaganda de espetáculos - em direção à celebridade, nome próprio conhecido por si mesmo. $\mathrm{Na}$ organização do material coletado, acompanhamos a categorização temporal da Biblioteca Nacional pelas três décadas de publicações identificadas: 1940-1950, 19501960 e 1960-1970. Em seguida, destacamos os anos em que houve mais recorrência na aparição do nome Luz del Fuego: entre 1950 e 1956, 1959 e 1967. ${ }^{3}$ Luz del Fuego era pauta de jornais standards de grande circulação naquele momento, como Correio da Manhã, Diário da Noite e Diário Carioca, e também de revistas - Revista do Rádio, O Cruzeiro, Careta e Revista da Semana. A maior parte dos textos encontrados foram matérias, reportagens e notas jornalísticas; fotografias da artista eram mais comuns nas revistas. Luz del Fuego, assim, apareceu em publicações humorísticas, jornalísticas, artísticas e ilustradas, a partir de temas relacionados ao teatro e ao carnaval, mas também a assuntos não usualmente relacionados às celebridades femininas: política, polícia e justiça. O mapeamento inicial resultou na seleção de cerca de 250 textos, observando matérias, notas, colunas, críticas e reportagens que permitissem analisar eventos e situações vividas por Luz del Fuego. 
A preocupação central deste artigo dá continuidade a trabalhos anteriores, realizados no âmbito de um projeto de pesquisa em desenvolvimento. A partir da compreensão das relações entre celebridade, cultura e questões de gênero, estamos analisando trajetórias de mulheres famosas na mídia brasileira. Duas personagens investigadas foram francesas em visita ao Brasil: Sarah Bernhardt (ROCHA; LANA, 2017) e Brigitte Bardot (ROCHA; LANA, 2019), atrizes que estiveram aqui no período áureo de suas carreiras, entre 1886/1905 e 1964, respectivamente. A terceira celebridade foi Pagu (ROCHA; LANA, 2018 ), que desempenhou atividades artísticas e políticas entre 1930 e 1960. Em todas as análises, dois eixos metodológicos guiaram o trabalho: 1) a performance de gênero (como essas mulheres se posicionaram diante dos homens, do trabalho, da família, da política e da cultura) e 2) a performance midiática (como as celebridades manipularam os momentos e as situações na mídia). A metodologia busca indicadores analíticos que revelem os modos como celebridades femininas, ocupando o espaço da mídia, desempenham, atuam, encenam, aparecem, enfim, constituem seus papéis e representações, realizando suas performances como figuras públicas em situações narradas em periódicos impressos. (GOFFMAN, 1996). Neste artigo, prosseguimos a investigação a partir dos mesmos eixos metodológicos, agora associados às singularidades da trajetória de Luz del Fuego que envolve, em linhas gerais, o erotismo, a violência, a moralidade, a censura e a política no Brasil.

Assim como nos casos das personagens estudadas anteriormente, muito pouco foi produzido sobre Luz del Fuego no Brasil. Além da biografia mencionada (AgOSTINHO; PAULA; BRANDÃO, 1994), existe uma publicação (MENEZES, 2011) que traz a trajetória da atriz associada a trechos da autobiografia $A$ verdade nua, cujo prefácio foi assinado por Plínio Salgado. Luz del Fuego escreveu também o romance Trágico Blackout. Ambos os livros de sua autoria estão indisponíveis. Há o documentário A nativa solitária, produzido em 1954, restaurado pelo Arquivo Público do Espírito Santo, e o longa-metragem Luz del Fuego (BRA, 1982), protagonizado por Lucélia Santos. O roteiro do filme, escrito por Aguinaldo Silva e Joaquim Vaz de Carvalho (1982), foi publicado na época. Assim como Pagu, ela foi lembrada por Rita Lee na canção Luz del Fuego, gravada no álbum Fruto Proibido, em 1975.

Com relação a estudos acadêmicos, Luz del Fuego aparece em esparsas pesquisas no campo da história (ALVES; FREITAS, 2016; BUENO, 2012) e do lazer (ANDRIEU; NÓBREGA, 2016). Nada muito consistente foi escrito sobre Luz del Fuego em pesquisas sobre relações de gênero e sexualidade. Nas principais revistas do Brasil, Cadernos Pagu e Estudos Feministas, 
por exemplo, não há nenhuma menção a ela - a não ser pela resenha da biografia Luz del Fuego, a bailarina do povo, publicada pela Estudos Feministas (LAPEIZ, 1994). Na biblioteca de teses e dissertações da Coordenação de Aperfeiçoamento de Pessoal de Nível Superior (CAPES), tampouco foi possível localizar estudos sobre a artista.

"Garota-propaganda dela mesma", existencialista", "imoral", "a mais discutida do Brasil", "ofídica senhora", "discutida, combatida, aplaudida", "original”, “atraente”, "louca”, "gorda senhora": Luz del Fuego foi intensamente avaliada por articulistas, críticos teatrais, colunistas sociais e jornalistas no material coletado para esta pesquisa, cerca de 250 textos publicados em periódicos nacionais entre 1930 e 1970. Foi possível identificar quatro eixos, que correspondem aos temas que marcaram a trajetória de Luz del Fuego na mídia, que orientam a análise a seguir.

\section{Carnaval e mídia}

O carnaval representou, nos primeiros anos da trajetória de Luz del Fuego, um acontecimento de grande promoção de sua imagem. Causava muita repercussão a vedete ser constantemente expulsa ou barrada no Teatro Municipal, onde ocorria a principal festa de carnaval do Rio de Janeiro, frequentada por políticos, como o presidente da República, embaixadores, militares, socialites e artistas.
Como explicava a Revista da Semana, o baile do Municipal, financiado pela prefeitura, era "famoso e internacional", onde os turistas encontravam "ambiente de luxo e conforto" (BAILE ..., 1949).

Em 1948, Luz del Fuego compareceu ao Municipal como Eva no Paraíso, "[...] uma sumaríssima fantasia, cujo peso não ultrapassava umas duzentas e cinquenta gramas... Resultado. O prefeito despejou-a sendo o assunto objeto de comentários em toda imprensa nacional." (COLÔNIA..., 1949, p. 10). Nos anos seguintes, a possibilidade de ser barrada ou entrar e ser expulsa - o que lhe rendeu o apelido "barracão" - fazia com que sua presença fosse sempre noticiada com destaque no carnaval.

Em 1950, fantasiada de Yemanjá, um maiô coberto por estrelas do mar e cabelos pintados de verde, Luz del Fuego permaneceu por quatro horas na porta do Teatro Municipal, buscando, mesmo com ingressos comprados, a aprovação para entrar no baile, o que não aconteceu. Em 1951, vestiu-se novamente de rainha do mar, fotografada em destaque no Diário Carioca. "Um grande peixe adaptado à perna esquerda, um polvo abraçando o tórax da bailarina, conchas e pérolas em profusão, uma rica cabeleira verde garantirão plenamente o cartaz da fundadora do Partido Naturalista Brasileiro" (FUNDO..., 1951, p.12). 
Mais uma vez, não pôde entrar. Em 1952, finalmente, participou do baile do Municipal. Vestida de "noiva existencialista", menção ao noivado desfeito com o maestro Eleazar de Carvalho naquele ano, Luz del Fuego deixou a festa mais cedo, segundo a Revista do Rádio, aborrecida por não ter sido classificada no concurso de melhor fantasia. Em 1953, não brincou o carnaval, anunciando que iria "[...] para a Ilha do Sol, de sua propriedade, onde fantasiada de 'gota d'água' meditará sobre a infelicidade que paira sobre seus compatriotas. [...] 'Atualmente não é época para gastos perdulários. Prefiro ficar na minha ilha pensando no que terei que fazer depois do carnaval" (Luz..., 1953, p. 6). Lá, naquele ano, ela pretendia realizar um baile nudista de carnaval, o que, segundo a revista Careta, não teria sido autorizado pelo governo, mas que foi narrado, em 2017, por um morador de Paquetá: “[...] um concorrido baile de carnaval na colônia, embalado por músicos que vestiam apenas gravata-borboleta." (HADDAD, 2017, p. 4).

Para o colunista Agnello Macedo (1950), ter sido expulsa do Municipal, em 1948, foi decisivo para a aparição midiática de Luz del Fuego.

Era a determinação e não a vocação que a levava a se pretender fazer bailarina. Um turumbamba aqui, um salseiro ali adiante, uma expulsão do Municipal quando foi a um baile fantasiada de Eva no duro, e Luz del Fuego sempre tirou uma casquinha, até que seu cartaz de manchete teve força suficiente para levar seu nome até o luminoso Teatro do Recreio, ao lado de Dercy Gonçalves e Linda Batista. Era atração de bilheteria. Toda a gente queria ver como era a moça da cobra. (MACEDO, 1950, p. 9).

A percepção que Luz del Fuego tinha poucos talentos artísticos, mas muita vocação para aparecer na mídia foi compartilhada por outros articulistas e em diversos momentos de sua trajetória. A coragem e o esforço para dançar nua com serpentes - ao longo dos anos, ela foi mordida várias vezes - eram admiráveis e destacavam seu nome no teatro de revista. "Apesar do fogo que tem no seu nome de guerra, é das frias serpentes que ela gosta. Esta entrou no palco da fama sem roupa e montada numa cobra. Vários e complexos são os caminhos que conduzem à celebridade, com aspas ou sem elas, mas o escolhido pela falada bailarina é, sem dúvida, realmente original." (CAYENA, 1952, p. 18).

Os textos analisados sugerem que a vedete tinha consciência que promovia sua própria imagem, elaborando calculadamente uma performance midiática. Na revista A Cigarra, o repórter Marcel Cognac (1948, p. 135) registrou: "[...] quem não a conhece pessoalmente, conhece de vista ou através das fotografias, de vez em quando publicadas em jornais e revistas, sempre com uma legenda nova em que 
ela própria anuncia mais de uma de suas iniciativas. Não raro protagoniza um pequeno escândalo." Para o baile do Municipal, “[...] devem estar lembrados os leitores", Luz del Fuego "[...] rumou, vislumbrando a publicidade que naturalmente ganharia. [...] Os fotógrafos presentes, ansiosos por sensacionalismo, viveram uma grande noite.” (p. 135).

Além de debater a participação de Luz del Fuego no baile do Teatro Municipal, as páginas dos jornais e revistas também se ocupavam, ano a ano, dos bastidores da disputa pelo título de rainha do carnaval. Em 1950, apesar de ter sido destaque no pré-carnaval de rua na "princesinha do mar", desfilando em cima de um carrinho de sorvete, Luz del Fuego perdeu a disputa para Elvira Pagã, com quem rivalizava pelas atenções da mídia. Naquele ano, a simples presença de Luz del Fuego na sede da Associação de Cronistas Carnavalescos para fazer inscrição ao concurso de rainha do carnaval carioca despertou comoção. "Não há naturalmente nesta cidade quem não conheça Luz del Fuego ou a 'bailarina das cobras', como é mais conhecida. Pois Luz del Fuego deu ontem a nota de sensação do dia. Ela, com todo o exotismo que a caracteriza, compareceu à sede da Associação de Cronistas Carnavalescos." (LUZ..., 1950, p. 5). Ela ainda foi, na primeira metade dos anos 1950, homenageada por blocos de rua do Rio de Janeiro.

Especulações em torno da imoralidade e do preço de suas fantasias compunham também a intensa visibilidade de Luz del Fuego durante os carnavais cariocas no final dos anos 1940 e meados dos 1950. Sem avareza, em 1954, ao contrário do ano anterior, “[...] ela reuniu suas economias, foi à cidade e comprou, entre outras coisas, cerca de 2 mil pedras lapidadas, imitando as preciosas. Só nesse detalhe gastou aproximadamente 25 mil cruzeiros!"4 (BORELLI FILHO, 1954, p. 20). Durante o carnaval, jornais de grande circulação traziam em destaque fotografias de Luz del Fuego fantasiada; no retrato na revista Life, Luz del Fuego era a "a garota da sociedade que desertou para o show business" (LIFE, 1951, p. 126). ${ }^{5}$

Na história do conceito de visibilidade, Nathalie Heinich (2012) argumenta que a mídia foi responsável por criar a noção de visibilidade

4 De acordo com o conversor de moedas do Jornal O Estado de São Paulo, Cr\$25.000,00 equivaleria hoje a $\mathrm{R} \$ 125.000,00$.

5 Ao contrário do que se afirma em sua principal biografia e no verbete "Luz del Fuego" da Wikipedia, ela nunca foi capa da revista Life. 
como capital, ${ }^{6}$ usado para a sobrevivência, passível de valorização ou desvalorização, transmissão ou estocagem, acumulação ou dilapidação. Como uma espécie de capital social (BOURDIEU, 1998), o capital de visibilidade relaciona-se a recursos ligados a uma rede de relações sociais duradouras e úteis. Nesse sentido, as celebridades buscam aumentar sua projeção midiática e seu capital através da mobilização das atenções para si.

Durante o carnaval, Luz del Fuego investia no aumento de seu capital de visibilidade - e o utilizava como forma de alcançar valor social em outras épocas do ano. Assim, o carnaval foi uma parte relevante da imagem pública de Luz del Fuego - não apenas pelo aumento de sua presença visual na mídia, mas também porque, mesmo fora do período carnavalesco, ela usava roupas e acessórios que remetiam à festa, sobretudo os vestuários sumários e os figurinos usados nos teatros. Em uma época em que o biquíni era proibido, o carnaval tornava a identidade de Luz del Fuego associada à transgressão, típica das representações populares, no sentido atribuído por Mikhail Bakhtin (1999).

\section{Erotismo e censura}

Muitos textos analisados noticiaram suspensões de espetáculos estrelados por Luz del Fuego e suas desavenças com a justiça em razão da censura. No começo dos anos 1950, era comum ler sobre apresentações de Luz del Fuego sendo proibidas em cidades de norte a sul do país. Em Belém, a "Câmara Estadual” recebeu discursos de protesto, com críticas à "[...] licenciosidade de traje com que a atriz se apresenta ao público desvendando aos olhos cobiçosos todos os recônditos de suas formas. [...] a atividade da atriz é exploração incompreensível da licenciosidade que leva à lares cristãos a luxúria e a depravação." (VerberadAs..., 1949, p. 13). Em São Paulo, "[...] a famosa nudista fora intimada a vestir mais roupa em cena na revista que exibe ao povo da Pauliceia." (ARAújo, 1951, p.42). Em Belo Horizonte, o imbróglio envolveu sua família, que armou um complô com a justiça para proibir suas apresentações (AGOSTINHO; PAULA; BRANDÃO, 1994). O juiz mineiro declarou a exibição “[...] imprópria não só para menores como para maiores, devendo o Estado estender a uns e outros seu manto protetor." (PINGOS..., 1950, p. 04). 
O manto protetor traduzia-se, literalmente, na instalação de uma cortina na frente do palco, denominada "véu da moral", para evitar a exposição direta da nudez.

0 serviço de censura multou, em sete mil cruzeiros ${ }^{7}$, a companhia teatral Juan Daniel, porque, em sua revista "A verdade nua", em cartaz num dos teatros da cidade e da qual são as maiores atrações as vedetes Elvira Pagã e Luz del Fuego, foi apresentada uma cena de mulheres desnudas sem que à boca do palco houvesse a obrigatória cortina diáfana destinada a filtrar de imoralidade a sensação de belo que se irradia no nu artístico das "girls". [...] o empresário Juan Daniel explicou que, quase à hora da exibição do quadro, a tal cortina do pudor rasgou-se, não tendo sido possível sua substituição. 0 exame da peça, porém, desmentiu-o: a cortina estava virgem. (EXIBIA..., 1952, p. 1).

Outras situações foram também dignas de notas na imprensa: a apreensão pela polícia da Revista de Copacabana, em 1950, e do filme Colônia de nudismo, em 1951. O "tribunal" de moral do Serviço de Censura às Diversões Públicas, criado em 1952, era o órgão responsável por essa fiscalização, sendo “[...] integrado pelo diretor da censura, um educador, um médico pediatra, especializado em assuntos de psicologia infanto-juvenil, dois jornalistas, pelo delegado de costumes e pelo juiz de menores." Naquele ano, o filme Saúde e Nudismo, de Luz del Fuego, por exemplo, foi considerado impróprio para qualquer idade por "[...] motivos de ordem ética, técnica e artística." (O TRIBUNAL..., 1952, p. 03).

De acordo com Luz del Fuego, a nudez tinha como fundamento as ideias naturistas, princípio ético que florescia na Alemanha e na França naquele momento. "Sou naturalista, não sou imoral. Cultuo a natureza acima de tudo. [...] Sou mal compreendida pelo público. Não prego a corrupção nem a lubricidade, recomendo e uso apenas a salutar precariedade da roupa, porque só há mente sã, onde há um corpo são." (EU..., 1951, p. 25). Dizendo ser vegetariana e defensora dos animais, Luz del Fuego criticava, desde suas primeiras aparições na mídia, a ingestão de bebida alcoólica, o cigarro ou o uso de qualquer tipo de droga. Na entrada da Ilha do Sol, uma placa advertia: "Nesta ilha é proibido proferir palavras de baixo calão e também a práticas de atos indecorosos. O nudismo só pode ser entendido por aqueles que possuem mente sadia." (AgOSTINHO; PAULA; BRANDÃO, 1994, p. 261). Em que pese seu discurso e mesmo sendo vista como uma mulher articulada, que dominava teorias filosóficas, como o existencialismo, a nudez mantinha o permanente "escândalo" em torno 
de seu nome, o que lhe conferia a imagem de pessoa desajustada.

Depois de dirigir seminua, em Botafogo, um carro conversível, Luz del Fuego foi presa e processada em 1953. O Ministério Público solicitou então que ela se submetesse a testes de sanidade mental. Em julho de 1955, o Diário Carioca anunciava que Luz del Fuego seria internada por ser "louca presumível". À Revista do Rádio, ela declarou: "Doido é quem me chama de louca!". “- Mas esse negócio de internação no hospital não assusta você?", indagou o repórter da revista. “- Qual, meu velho, não conseguirão! [...] para ser internada num hospício é preciso que toda a justiça brasileira fique doida primeiramente", Luz del Fuego respondeu. (DoIDO..., 1955, p. 26). Poucos meses depois, em setembro, o Correio da Manhã noticiava que ela havia sido absolvida.

Pendências judiciais semelhantes se arrastaram no noticiário no final dos anos 1950, envolvendo sobretudo a nudez na Ilha do Sol. Em junho de 1959, os trabalhadores que construíam uma boate no clube de naturismo entraram em greve depois da chegada do inverno; obrigados a trabalhar nus, solicitavam à justiça que pudessem vestir roupas devido ao frio. Em agosto do mesmo ano, Luz del Fuego negaria, em audiência na "Delegacia de Costumes e Diversões" a obrigação supostamente imposta aos trabalhadores. Em 1960, o serviço de recenseamento foi impedido de entrar na Ilha do Sol, uma vez que não concordaram em se despir para realizar a checagem do número de moradores do local. No mesmo ano, a TV Tupi realizou uma reportagem com Luz del Fuego, em que o entrevistador precisou ficar nu, imagem reproduzida pela Revista do Rádio.

Ao fundar e administrar praticamente sozinha o clube na Ilha do Sol, que teve cerca de 200 sócios em meados dos anos 1950, Luz del Fuego mostrava que, para além dos escândalos midiáticos, ela realmente acreditava no naturismo. O naturismo - e não as aspirações da mulher dos anos dourados - foi seu projeto de vida: Luz del Fuego nunca se casou (desfez noivados duas vezes) ou teve filhos (cuidou durante alguns meses de um bebê de uma bailarina do teatro de revista), morando na Ilha do Sol até sua morte.

\section{Polícia e justiça}

O nome Luz del Fuego associou-se à polícia - houve episódios de prisões, assaltos, denúncias de violência, variados crimes e delitos - e à justiça - ela foi processada em tribunais trabalhista e penal e participou também como testemunha de julgamentos. Nesse sentido, o acontecimento mais marcante foi o seu brutal assassinato por dois pescadores em julho de 1967. 
Em 1950, jornais noticiaram um golpe com o nome de Luz del Fuego. Em Belo Horizonte, um homem se dizia deputado federal filiado ao Partido Naturalista - que nem existia oficialmente - e que precisava de um suplente na Câmara Federal. Para isso, o golpista pedia uma importância em dinheiro e prometia que "[...] os deputados do Partido Naturalista tinham o direito de usar e abusar de sua orientadora. Quem ocupasse a sua vaga na Câmara também o substituiria junto àquela bomba hidrogenada...". (LUz..., 1950, p. 03). Na Revista da Semana, o caso foi intitulado “Deputados a CR. 5.000,00", valor cobrado pelo golpista.

Naquele mesmo ano, em 1950, Luz del Fuego anunciava na mídia que iria mover uma ação na justiça do trabalho contra o famoso empresário teatral Walter Pinto. Ele não haveria pago a remuneração pela atuação no espetáculo "Catuca por baixo" e ainda teria retido figurinos e cenários que pertenciam a Luz del Fuego. Nas semanas seguintes, era o empresário quem efetivamente a processava por calúnia e difamação. Segundo o Correio da Manhã, na audiência de conciliação, em 30 de novembro de 1950, Luz del Fuego não se retratou, e o processo seguiu adiante, não recebendo depois atenção dos jornais.
Em 1949, sua casa na avenida Niemeyer foi furtada enquanto ela excursionava pelo norte do país. Ao longo dos anos, outras notícias de furtos e assaltos às suas residências são noticiadas - alguns na Ilha do Sol, onde ela passou a viver em meados dos anos 1950. Na primeira vez, “[...] o ladrão ou os ladrões carregaram uma rádio-vitrola de alto preço, com discos, talheres e alguns outros objetos. Só ficou uma faca de cortar carne." (ASSALTARAM..., 1949, p. 09). Ao jornal Correio da Noite, ela listou outros bens furtados: uma coleção de perfumes franceses, roupas de linho e seda, cortinas, um colar de ouro e um brinco de ouro com rubi. Quando indagada se estaria com medo, ela respondeu: "Nada temo. Não tenho receios. Tenho minhas cobras - o que é bastante para garantir-me. Soltá-las-ei no assoalho, próximo à porta por onde o ladrão entrou. Duvido que ele consiga atravessá-la sem ser violentamente atacado por minhas 'jiboias'." (ASSALTO..., 1949, p. 28). No dia seguinte, O Jornal repercutiu a declaração, ironizando que Luz del Fuego teria desafiado os ladrões para um segundo assalto, lançando a pergunta: "Qual o novo Adão que quer perder outra vez o paraíso?”. (UM CASO..., 1949, p. 05).

As demais invasões aconteceram em 1953, 1956 e 1965 - além do derradeiro episódio de 1967, 
quando os assassinos assaltaram a Ilha do Sol e mataram Luz del Fuego e seu caseiro. Em 1953, móveis, janelas, portas, latas de tinta e sacos de cimento foram levados da ilha onde Luz del Fuego preparava a construção do clube de naturismo. Na breve nota sobre o assalto, o Correio da Manhã ironizou: Luz del Fuego "[...] acreditava que ninguém soubesse o caminho da ilha." (VAmos..., 1953, p. 03). A Revista Careta também zombou: “[...] uma grande sorte que os ladrões tenham agido na ausência dos sócios, pois é certo que os deixariam sós com a roupa do corpo..." (COMÉDIA..., 1953, p. 10).

Em 1956, uma casa que construía no Recreio dos Bandeirantes, no Rio de Janeiro, foi demolida durante a madrugada, sendo ela e sua empregadas despejadas de maneira violenta. Entre 1957 e 1958, os jornais deram conta dos desdobramentos jurídicos do caso: Luz del Fuego alegava que, antes de construir a casa, havia se certificado que o lote não pertencia a ninguém e que iria solicitar o aforamento ao Ministério da Marinha quando terminasse a obra. Por sua vez, a Companhia Recreio dos Bandeirantes Imobiliária alegava o direito sobre o terreno. Luz del Fuego afirmava que, mesmo perdendo a propriedade, entraria com um pedido de indenização por ter sido espancada. Em 1958, houve o desfecho do caso, arquivado por prescrição.

Em 1965, dois episódios de invasão da Ilha do Sol são reportados. Um em setembro, quando uma mulher, Valci Carvalho Pagliassi, teria adentrado no "mundo de nus" e feito uma "limpeza geral", levando “[...] I relógio, dois anéis e CR \$15 mil9, além da calça predileta da acidentada nudista." (ROUBO..., 1965, p. 20). Ao delegado, Luz del Fuego protestara especialmente sobre a calça de helanca, o que, na conclusão da matéria, o Diário de Notícias ironizou - Valci, a acusada, teria perguntado aos investigadores "[...] para que queria em sua ilha de nus uma calça assim?". Em uma charge, Luz del Fuego aparece distraída alimentando uma serpente, enquanto uma mulher, em um barco, se afasta da ilha com objetos nas mãos, com a legenda: "Roubo na Ilha do Sol: Luz del Fuego ficou sem roupa". (RоUво..., 1965, p. 20).

O outro episódio de 1965 ocorreu em agosto, quando quatro homens invadiram a ilha, agrediram o caseiro Edgar e ameaçaram estuprar Luz del Fuego, que não estava em casa. Na denúncia à polícia, Luz del Fuego registrou que nada havia sido levado; aos jornalistas, ela afirmou novamente não ter medo nem de "piratas do mar", nem de "ratos de 
praia", prometendo afogá-los em um próximo roubo. Dois anos depois, em 1967, ocorreria seu assassinato.

\begin{abstract}
Há muito a colônia deixara de ser um lugar seguro. Fechado o clube, sua vulnerabilidade aumentara. Agora raramente recebia visitantes, muitos deles intrusos que the causavam problemas. Ladrões que iam roubar seus poucos pertences ou arruaceiros que invadiam a ilha com a intenção de violentá-la. Por causa disso, comprara outra arma e rechaçava as investidas a bala. Às vezes, arriscava uma queixa no Distrito Policial de Neves, onde era recebida como uma vagabunda qualquer. "Desguie. Desguie, belezura. Quem mandou fazer ponto numa ilha?" (AGOSTINHO; PAULA; BRANDÃO, 1994, p. 233-234).
\end{abstract}

Com destaques de capa, jornais acompanharam, entre julho e agosto de 1967, o desaparecimento de Luz del Fuego e do caseiro Edgar, as investigações, a busca pelos corpos das vítimas, a retirada dos cadáveres do mar, a apreensão dos objetos roubados, as prisões dos acusados, a confissão e o julgamento dos criminosos. A revista O Cruzeiro foi a publicação que melhor sintetizou o crime, com textos, fotografias e uma entrevista póstuma com Luz del Fuego. Em 19 de julho de 1967, os irmãos Mozart Teixeira Dias e Alfredo Teixeira Dias aproximaram-se silenciosamente da Ilha do Sol e levaram, sem que ninguém visse, o barco de Luz del Fuego. Pouco tempo depois, avisaram a ela do furto e ofereceram carona para que pudesse reaver sua embarcação.
Sozinha com os irmãos, Luz del Fuego foi covardemente morta com pancadas de remo na cabeça, desferidas por Alfredo, que confessaria mais tarde o crime. Em seguida, eles retornaram à ilha para matar o caseiro Edgar, que estava sozinho. Depois do duplo homicídio, os Mozart e Alfredo precisavam se livrar dos corpos. "Pegaram a baleeira que estava no galpão e levaram para água. Abriram a faca o ventre dos dois cadáveres e os amarraram juntos no fundo do pequeno barco. Depois encheram-no de pedras e manilhas e o rebocaram 400 metros fora para afundá-lo. Voltaram à ilha para o saque. Levaram o que puderam" (AUDI, 1967, p. 12).

O assassinato, primeiramente, havia sido tratado como mais uma tentativa de Luz del Fuego para aparecer na mídia, um "golpe publicitário". Quase vinte anos após a expulsão do Municipal, jornalistas mostravam-se reticentes com a possibilidade de serem usados para elevar o capital de visibilidade (HEINICH, 2012) da vedete - prevenidos dos investimentos que Luz del Fuego sabia, há quase duas décadas, fazer. Em menos de uma semana, contudo, o caso passava a ser tratado como "obra diabólica", "macabra" e um "dos mais bárbaros latrocínios dos últimos tempos". Jornalistas e fotógrafos participaram de maneira próxima das investigações, não apenas registrando momentos como a retirada dos corpos do mar, mas também 
recebendo pistas sobre o caso. "Uma semana após o desaparecimento de Luz del Fuego, o repórter Mauro Dias recebeu na redação do jornal O Dia um estranho telefonema. [...] 'Olha, eu sei quem deu sumiço na mulher das cobras e no empregado dela...." (AGOstinHO; PAULA; BRANDÃO, 1994, p. 235). A informação, que também foi recebida pelo jornal última Hora, era verdadeira.

Luz del Fuego conhecia os criminosos: ela havia denunciado à polícia que os irmãos Mozart e Alfredo estariam pescando com o uso de dinamite nos arredores da Ilha do Sol, o que fez com que eles passassem a ameaçá-la. Uma carta endereçada ao governador do estado, Jeremias Fontes, descoberta durante as investigações, sugeria que nada havia sido feito para resolver o problema, ao contrário, Luz del Fuego "[...] denunciava ter sido destratada na delegacia de Neves, quando lá foi revelar o esconderijo de bandidos [...]. A nudista se dizia indignada com o tratamento recebido na delegacia." (AGOSTINHO; PAULA; BRANDÃO, 1994, p. 232).

O sepultamento de Luz del Fuego no Cemitério São João Batista, no Rio de Janeiro, teve grande repercussão midiática, sendo noticiado por jornais e revistas. Seus irmãos vieram de Belo Horizonte e do Espírito Santo para providenciar a cerimônia. "O enterro, pouco concorrido, contou com a presença de amigos, fãs e curiosos, ressentindo-se da presença de artistas. Destes, apenas compareceu Lúcia Helena, contando-se entre outros alguns 'travestis' do chamado teatro do rebolado." (GAguinHo..., 1967, p. 13). O destaque ao esvaziamento da cerimônia e a presença da família - com quem ela não convivia - e de personagens transgressores sugeriram uma "lição moral" para o desfecho da trajetória de Luz del Fuego. A imprensa reconheceu a morte brutal da artista como um crime abominável, mas, ao mesmo tempo, a tragédia parece ter sido tratada como punição. A dúvida se havia, de fato, ocorrido um assassinato, a recapitulação dos riscos que corria vivendo na Ilha do Sol e a ausência de multidões ou de celebridades importantes no enterro mostraram o dilema entre condenar francamente a tragédia ou utilizar o caso como uma lição.

Jornais e revistas ainda passariam algumas semanas noticiando o caso: o principal acusado demorou a ser encontrado pela polícia e, em uma das tentativas de prisão, matou um policial com cinco tiros. Os bens de Luz del Fuego foram disputados por sua família, uma vez que o tão anunciado testamento para a Sociedade Protetora do Animal nunca foi feito. "E disputaram a herança - o domínio útil da Ilha do Sol e a casa da Niemeyer - com o mesmo empenho com que combateram e ignoraram a irmã em vida." (Agostinho; PAULA; BRANDÃO, p. 256-257). 


\section{Política e poder}

Um último tema na trajetória de Luz del Fuego, a política, foi também um dos mais significativos. Um ano depois de alcançar notoriedade por ter sido expulsa do baile do Municipal, Luz del Fuego ganhou nova projeção ao anunciar a criação do Partido Naturalista Brasileiro, em 1949. Assim, as notícias sobre o partido fizeram com que ela também ocupasse as páginas reservadas ao noticiário de política - ela parece ter transitado, portanto, por quase todas as seções dos periódicos brasileiros. Pouco antes, em 1932, as mulheres haviam conquistado direitos políticos no Brasil. Apesar de não ser lembrada em análises que tratam da questão do sufrágio feminino, o material analisado sugere que Luz del Fuego contribuiu, bem à sua maneira, para a percepção da mulher brasileira como sujeito de direitos políticos.

Em setembro de 1949, as primeiras notícias sobre o Partido Naturalista: os jornais buscavam explicar diretrizes e alianças do partido; intenções e possibilidades de realização das propostas de Luz del Fuego. Na capa do Diário da Noite, com a linha fina "incêndio na política”, ela prometia que, como deputada, iria para Câmara "[...] em trajes curtos e leves. Garanto que nenhum deputado faltará às sessões. Haverá permanente 'quórum' e portanto, muito trabalho. Luz e fogo. Precisamos acabar com o protocolo, o colarinho e a gravata."
(Vou..., 1949, p. 1). O "partido da natureza" seria contrário ao "partido dos preconceitos", e possuía propostas objetivas, sumarizadas no Diário da Noite e também divulgadas em outros jornais: proteção aos artistas, às mulheres e aos animais, divulgação da música brasileira e do folclore indígena, proteção ao espiritismo e à macumba, legalização do divórcio, liberdade para o jogo e incentivo à ocupação do interior do Brasil. O partido ainda declarava apoio a Oswaldo Aranha (que, na verdade, nem se candidatou) nas eleições presidenciais de 1950 e lançava a candidatura de Luz del Fuego à Câmara dos Deputados.

Na apresentação do partido, Luz del Fuego tratava de temas de interesse público associados com sua visão particular de mundo. Na coluna Pingos $\&$ Respingos (1949, p. 04), citou Nietzsche para justificar que "[...] ninguém pode ser grande ou importante se não souber bailar." Ao defender o nudismo, questionava a liberdade plena de manifestação na democracia. Para conseguir cumprir os requisitos para a criação do partido, não hesitou em se apresentar cobrando, como ingresso, assinaturas de filiação. Em entrevista à Revista do Rádio, fez questão de entregar ao repórter panfletos do PNB, que divulgou as principais frases inscritas no material: "Para a fome, temos o pão; para a sede, a água; para imoralidade, a nudez - Luz del Fuego. [...] O Partido Naturalista Brasileiro é uma verdade entre as promessas 
do Brasil." (VAI..., 1950, p. 7). A reportagem não tratava de política, mas, sim, do novo projeto de Luz del Fuego - tornar-se uma artista do rádio. Entretanto, nem ela se tornou cantora, nem o partido foi criado.

Em setembro de 1950, a Folha da Tarde noticiava que o "memorial" com 50 mil assinaturas necessárias para a criação do Partido Naturalista Brasileiro se perdera em um acidente aéreo, que havia vitimado o senador Salgado Filho. Luz del Fuego explicou ao jornal:

Já estava quase registrado meu partido. Para que ele fosse realmente forte, eu queria obter a adesão de um grande figurão da política. Por isso, dirigime ao sr. Salgado Filho, que me recebeu muito bem, dizendo que ia entenderse com o senador Getúlio Vargas para esse fim. Na ultima viagem que ele empreendeu ao Sul, levou consigo o meu memorial [...]. Faça ideia, agora, como sofri, quando tive noticia do trágico desastre em que pereceu o senador Salgado Filho, pois, como sabia, o documento assinado pelos meus eleitores também havia sido queimado no horrível desastre... (DEVORADAS..., 1950).

Entretanto, há outra versão para a perda das assinaturas: o irmão de Luz del Fuego, senador Attilio Vivacqua, não aprovava a nascente carreira política da irmã e teria destruído o memorial. Segundo a biografia de Luz del Fuego, a família também foi responsável por sumir com quase toda a tiragem dos livros escritos por ela. "Deixar vir à tona o parentesco com uma vedete era o meio mais eficaz de manchar o nome dos Vivacqua." (AgostINHO; PAULA; BRANDÃO, 1994, p. 180). Especialmente, Attilio "[...] encetara uma guerra sem tréguas contra Luz. [...] Chegava a comprar edições inteiras de revistas que publicavam fotos da irmã." (p. 180).

Apesar da fracassada fundação do partido, Luz del Fuego manteve-se próxima da política. Para conseguir o aforamento da Ilha do Sol, no início dos anos 1950, a vedete transitou pelos altos escalões do governo Vargas. Em 1955, o candidato à presidência Plínio Salgado utilizou em sua campanha presidencial o texto $A$ mulher nua, em que defendia a vedete e a nudez como críticas ao "falso moralismo" da burguesia brasileira. ${ }^{10}$ Além disso, o filme Luz del Fuego (BRA, 1982) inspirou-se na relação da vedete com a política: o romance com o senador João Gaspar (Walmor Chagas) é o fio condutor da história, que rememora a tentativa de criação do Partido Naturista Brasileiro e a proximidade de Luz del Fuego (Lucélia Santos) com deputados. Luz del Fuego, assim, 
aplicava seu capital para divulgar questões políticas que encampava, em uma simbiose que dava visibilidade às suas ideias e ainda trazia para sua imagem pública sentidos não usualmente associados à profissão de vedete. Ao se enveredar para a política, em uma rede de relações bem estabelecidas, ela se mostrava como alguém que conhecia os assuntos em discussão na vida social e que tinha ideias próprias.

A análise da trajetória de Luz del Fuego indica que ela soube ser um sucesso de escândalo, protagonizando casos que questionavam valores e convenções. Como discute Ari Adut (2008), o escândalo promove um "distúrbio moral" no espaço público, influenciando a vida social. "Por um lado, escândalos são um fenômeno profundamente moral. A reação do público é normalmente indignação - a emoção moral por excelência. Aqueles que expõem transgressões em público [...] são também motivados por ideais morais." ${ }^{11}$ (ADUT, 2008, p. 288, tradução nossa). Por outro lado, os escândalos podem ser vistos como "fenômeno profano". "Altamente contagiosos, eles arriscam macular todos os envolvidos. Eles possuem todos os tipos de efeitos secundários e consequências não intencionais, que podem parecer injustas, imorais e desmoralizadoras." ${ }^{12}$ (ADUT, 2008, p. 289, tradução nossa). Existe, assim, uma ambiguidade: colocando em discussão emoções, valores e modelos de conduta, os escândalos podem motivar tanto o aperfeiçoamento quanto a degradação da vida em comum. O escândalo pode, por exemplo, tornar normal qualquer tipo de transgressão - sem o aprimoramento de valores como respeito, justiça e honestidade - ou promover a fama dos envolvidos pelo simples fato de ter obtido visibilidade - a criação da celebridade, figura famosa em razão da mídia. ${ }^{13}$

Luz del Fuego representou resistência e superação aos padrões de comportamento de sua época - possivelmente dando voz a outras tantas mulheres anônimas do período, uma vez que, poucos anos após a morte de Luz del Fuego, condutas consideradas escandalosas, como dirigir de biquíni, por exemplo,

11 "On one hand, scandals are heavily moral phenomena. Public reaction to them is usually one of indignation - the moral emotion par excellence. Those who publicize transgressions, [...] are frequently motivated by moral ideals, too."

12 "Hightly contagious, they risk polluting all those with whom they come into contact. They have all kinds of third-party effects and unintended consequences that look injust, immoral, or demoralizing."

13 Em 1962, Daniel Boorstin (1992) lamentou o surgimento das celebridades. Sem qualidades e vazias, as celebridades, produzidas para serem vistas, não trariam nenhum benefício social, ao contrário dos heróis, dotados de valores positivos e desejáveis. Os celebrity studies analisam esses "famosos da mídia", examinando essas contradições. (MARSHALL, 2006). 
tornaram-se triviais. A mulher também conquistou, a partir dos anos 1970, mais liberdade e independência, características associadas à imagem Luz del Fuego. "Através do escândalo, o fraco pode se vingar do forte. Mas há algo perturbador nesse uso vingativo da moralidade, que, oriunda do ressentimento, tende a funcionar apenas quando o forte já não é mais assim tão forte.” ${ }^{14}$ (ADUT, 2008, p. 289, tradução nossa). A "vingança ressentida" da "fraca" Luz del Fuego contra a "forte" moral tradicional, portanto, foi possível porque o Brasil deixava a era dos modelos identitários rígidos e, provavelmente, esses valores tradicionais já estivessem se transformando naquele momento. ${ }^{15}$

De muitas maneiras, Luz del Fuego foi "domesticada": nossa pesquisa revelou que ela foi caracterizada como exótica (vivendo sozinha em uma ilha inóspita, dedicada aos animais e à natureza), erotizada (mal interpretada na divulgação do naturismo), vilã ameaçadora à estabilidade da família burguesa (solteira, sem filhos, não cumprindo o destino "natural" de uma mulher com seu perfil, realizando shows seminua), risível (expulsa tantas vezes do Baile do Municipal, assaltada e violada muitas vezes), ocupante de um lugar de destaque (uma celebridade), mas que era constantemente posicionada fora do que poderia ser considerado "sério" (foi anulada da política formal, não foi ouvida ao denunciar crimes ambientais ou a pregar ideias progressistas).

Mensurar o impacto exato de Luz del Fuego nas transformações sociais do Brasil urbano na década de 1950 iria muito além dos limites deste trabalho. A pesquisa mostrou, contudo, as inúmeras ambiguidades de sua trajetória. Os textos analisados sugerem que Luz del Fuego planejou uma carreira midiática, moldando sua performance com o intuito de "ser notícia". Determinada, dominou a dança com as cobras, percebendo que a excentricidade gerava bilheteria aos seus espetáculos; barrada no baile do Municipal, retornou outras vezes e permaneceu em evidência. Ela não afirmava explicitamente propósitos eróticos

14. "Through scandal the weak can avenge themselves against the strong. But there is something troubling in such vindictive use of morality, which, springing from ressentment, tends to succeed only after the powerful are no longer so powerful."

15 Esse tipo de mudança social pode ser observado em outros momentos, como no declínio do poder patriarcal no século XVIII, personificado, por exemplo, na trajetória de Xica da Silva. Como analisa Roberto da Matta (1976), Xica da Silva utilizou o "poder dos fracos". "Reprimida enquanto ser social, enquanto pessoa destinada a ter direitos, já que era uma escrava, Xica só pode atuar na esfera dos poderosos utilizando o poder que emana de seu corpo: sensual, firme, sadio." (DA MATTA, 1976, p. 18). 
na exposição do corpo, mas não hesitou em anunciar que trabalharia com roupas curtas e decotadas como deputada federal, em prol da assiduidade nas sessões da Câmara. A ideia de fundar um partido político se misturava a outras possibilidades - cantora, dançarina, ativista - ou seja, seu maior investimento pessoal e profissional era a própria mídia.

Muitos outros fatos interessantes de sua trajetória não couberam neste artigo: a viagem aos Estados Unidos, a curta carreira de paraquedista, as brigas com Elvira Pagã e a campanha para arranjar um marido na Revista do Rádio. Afirmava constantemente na mídia que seus problemas financeiros eram resolvidos com a família, proprietária do banco "Preconceito S.A.", que cedia diante da ameaça de exposição da intimidade dos Vivacqua. No início dos anos 1960, quando os sócios abandonaram o clube de nudismo, Luz del Fuego anunciava happenings de nudez em busca de recursos financeiros do governo e de bancos públicos para obras na Ilha do Sol - que ora ela anunciava como um hotel, ora como uma boate. Dona de capital de visibilidade, até os últimos momentos, ela tentou manejar os recursos que ainda possuía.

A pesquisa também revelou a zombaria com que era tratada - dos periódicos analisados, apenas a Revista do Rádio esboçava mais respeito por Luz del Fuego. O sarcasmo da mídia não se reduzia à crítica por sua pouca relevância artística para o canto ou a dança; a zombaria refletia muito mais tanto a indignação quanto o medo pelo perigo do distúrbio moral que sua imagem sistematicamente expressava.

\section{Referências}

A NATIVA SOLITÁRIA. Direção: Francisco de Almeida Fleming. Produtora: América Films. Brasil, 1954. Curta metragem (30 min).

ABU-LUGHOD, Lila. Melodrama egípcio: uma tecnologia do sujeito moderno? Cadernos

Pagu, n. 21, p. 75-102, 2003.

ADUT, Ari. On scandal: moral disturbance in society, politics, and art. Nova York: Cambridge University Press, 2008.

AGOSTINHO, Cristina; PAULA, Branca; BRANDÃO, Maria do Carmo. Luz del Fuego, a bailarina do povo: uma biografia. São Paulo: Editora Best Seller, 1994.

ALVES, Carlos; FREITAS, Ana Carolina. A construção da imagem de Luz del Fuego nos jornais brasileiros e a sua interferência na política capixaba das décadas de 30 e 40.

Temática, n. 4, p. 63-78, abr./2016.

ANDRIEU, Bernard; NÓBREGA, Terezinha. O naturismo como ecologia do corpo: um exemplo vivido na praia de Tambaba, Paraíba, Brasil. Licere, v. 19, n. 4, p. 34-59, dez./2016.

ARAÚJO, Manezinho. Rua da Pimenta. Revista do Rádio, Rio de Janeiro, p. 42, 04 set. 1951. ASSALTARAM a residência de Luz del Fuego. A Noite, Rio de Janeiro, p. 09, 10 dez. 1949. 
ASSALTO misterioso na casinha branca.

Diário da Noite, Rio de Janeiro, p. 28,

15 dez. 1949.

AUDI, Jorge. Sangue na Ilha do Sol.

O Cruzeiro, Rio de Janeiro, p. 11-13,

19 ago. 1967.

BAILE do municipal. Revista da Semana,

Rio de Janeiro, p. 20,12 mar. 1949.

BAKHTIN, Mikhail. A cultura popular na

Idade Média e no Renascimento: o contexto de François Rabelais. São Paulo: Hucitec, 1999.

BOORSTIN, Daniel. The image. A guide to pseudo-events in America. New York: Vintage Books, 1992.

BORELLI FILHO. Luz del Fuego desistiu do nudismo. Revista do Rádio, Rio de Janeiro, p. 20-13, 27 mar. 1954.

BOURDIEU, Pierre. O capital social: notas provisórias. In: CATANI, Alfredo; NOGUEIRA, Maria Alice (Org.) Escritos de educação.

Petrópolis: Vozes, 1998. p. 65-69.

BRIGHENTI, Andrea. Visibility: a category of the social sciences. Current Sociology, v. 55, n. 3, p. 323-342, maio 2007.

BUENO, Eric. Uma história visual da nudez e sensualidade feminina na revista $O$

Cruzeiro (1966-1970). 2012. 251 f. Dissertação (Mestrado)-Programa de Pós-Graduação em História, Universidade Federal de Santa Catarina, Florianópolis, 2012.

CAYENA, Celso. 12 tipos famosos da cidade.

A Cigarra, São Paulo, p.18, fev. 1952.

COGNAC, Marcel. A bela e a fera. A Cigarra, São Paulo, p.131-135, ago. 1948.
COLÔNIA de nudismo no Rio na Barra da Tijuca numa praia misteriosa. Diário da Noite, Rio de Janeiro, p. 10, 22. fev. 1949.

COMÉDIA infinita. Careta, Rio de Janeiro, p. 10,13 jun. 1953.

DA MATTA, Roberto. A hierarquia e o poder dos fracos. Opinião, Rio de Janeiro, p. 18-19, 15 out. 1976.

DEVORADAS pelo fogo as esperanças do Partido Naturalista. Folha da Tarde, São Paulo, 18 set. 1950.

DOIDO é quem me chama de louca! Revista do Rádio, Rio de Janeiro, p. 26-27, 13 ago. 1955.

DUBY, Georges; FRAISSE, Geneviève; PERROT, Michelle (Org.). História das mulheres no Ocidente: o século XIX. Porto: Edições Afrontamento, 1991. (v. 4).

EU não sou imoral! Revista do Rádio,

Rio de Janeiro, p. 24-25, 20 fev. 1951.

EXIBIA mulheres nuas, sem o véu diáfano da moral. Diário Carioca, Rio de Janeiro, p. o1, O5 set. 1952.

\section{FLAGRANTES. Correio da manhã,}

Rio de Janeiro, p. 2, 30 maio 1954.

FRIEDAN, Betty. Mística feminina. São Paulo: Vozes, 1971.

FUNDO do mar no Municipal. Diário Carioca, Rio de Janeiro, p. 12, 04 fev. 1951.

GAGUINHO ainda solto e polícia brigando com polícia por ciúmes. Diário de Notícias, Rio de Janeiro, p. 13, 03 ago. 1967.

GOFFMAN, Erving. A representação do eu na vida cotidiana. Petrópolis: Vozes, 1996. 
HADDAD, Naief. Os 50 anos da morte de Luz del Fuego, a vedete vanguardista. Folha de $\mathbf{S}$. Paulo, São Paulo, 19 mar. 2017.

HEINICH, Nathalie. De la visibilité: Excellence et singularité en régime médiatique. Paris:

Editions Gallimard, 2012.

LANDES, Joan. Women and the Public Sphere in the Age of French Revolution. Nova Iorque: Cornell University Press, 1988.

LAPEIZ, Sandra Maria. Perversa lucidez da nostalgia. Estudos Feministas, n. 2, ano 2, p. 543-545, 1994.

LIFE goes to the Rio Carnival. Life, Nova Iorque, p. 126, 26 fev. 1951.

LUZ del Fuego. Diário Carioca, Rio de Janeiro, p. 3, 14 maio 1950.

LUZ del Fuego. Correio da Manhã, Rio de Janeiro, p. 5, 20 jan. 1950.

LUZ del Fuego não vai fazer carnaval. Diário

Carioca, Rio de Janeiro, p. 6, 15 fev. 1953.

LUZ Del Fuego. Direção: David Neves. Produtora: Embrafilmes. Brasil, 1982. Longa metragem (95 $\mathrm{min}$ ).

MACEDO, Agnello. Fiat $+\mathrm{Luz}=\mathrm{Luz}$ del

Fuego. Correio da Manhã, Rio de Janeiro, p. 9, 23 ago. 1950.

\section{MARSHALL, P. David. The Celebrity Culture}

Reader. Nova York: Routledge, 2006.

MENEZES, Thiago. A verdadeira Luz del

Fuego. São Paulo: All Print Editora, 2011.

O TRIBUNAL de moral funcionará a partir da próxima semana. Correio da Manhã, Rio de Janeiro, p. 3, 27 jun. 1952.
MORIN, Edgar. As estrelas. Mito e sedução no cinema. Rio de Janeiro, José Olympio, 1989.

PAIVA, Salvyano. Viva o rebolado! vida e morte do teatro de revista brasileiro. Rio de Janeiro: Nova Fronteira, 1991.

PERROT, Michelle. Mulheres públicas.

São Paulo: Editora Unesp, 1998.

PINGOS \& respingos. Correio da Manhã, Rio de Janeiro, p. 4, 1 jun. 1950.

PINGOS \& respingos. Correio da Manhã, Rio de Janeiro, p. 4, 24 nov. 1949.

PINSKY, Carla Bassanezi. Mulheres dos Anos Dourados. In: PRIORE, Mary del (Org.).

História das mulheres no Brasil. São Paulo:

Editora Contexto, 2012. p. 607-639.

ROCHA, Everardo; LANA, Lígia. O jardim das delícias: os dilemas de Brigitte Bardot no Rio de Janeiro. Matrizes, v. 13, n. 1, p. 191-209, jan./ abr. 2019.

ROCHA, Everardo; LANA, Lígia. Imagens de Pagu: trajetória midiática e construção de um mito. Cadernos Pagu, v. 54, p. 185416, 2018.

ROCHA, Everardo; LANA, Lígia. Fama e afetação: as passagens de Sarah Bernhardt pelo Rio de Janeiro (1886-1905). Revista Famecos, v. 24, id.26222, 2017.

ROUBO na Ilha do Sol: Luz del Fuego sem roupa. Diário de Notícias, Rio de Janeiro, p. 20, 24 set. 1965.

SILVA, Aguinaldo; CARVALHO, Joaquim Vaz. Luz del Fuego. Rio de Janeiro: Codecri, 1982.

UM CASO por dia. O Jornal, Rio de Janeiro, p. 5, 16 dez. 1949. 
VAI entrar para o rádio a mais discutida

bailarina brasileira. Revista do Rádio,

Rio de Janeiro, p. 6-7, 05 jun. 1950.

VAMOS falar de mulheres? Correio da Manhã,

Rio de Janeiro, p. 3, 1953.

VERBERADAS as exibições de Luz del Fuego.

Correio da Manhã, Rio de Janeiro, p. 13,

o9 dez. 1949.

VOU levantar o Brasil de ponta a ponta. Diário

da Noite, Rio de Janeiro, p. 1, 03 out. 1949.

\section{Informações sobre 0 artigo}

Resultado de projeto de pesquisa de pós-doutorado: “Celebridades, gênero e receituários do consumo na publicidade brasileira".

Fontes de financiamento: Fundação Carlos Chagas Filho de Amparo à Pesquisa do Estado do Rio de Janeiro (FAPERJ), Coordenação de Aperfeiçoamento de Pessoal de Nível Superior (CAPES) e Conselho Nacional de Desenvolvimento Científico e Tecnológico (CNPq).

Código do processo do projeto financiado: E-26/202.149/2015

Considerações éticas: Não se aplica.

Declaração de conflito de interesses: Não se aplica.

Apresentação anterior: Trabalho apresentado no XXVIII Encontro Anual da Compós, 2019, Porto Alegre - RS.

Agradecimentos/Contribuições adicionais: Agradecemos aos pesquisadores do Grupo de Trabalho Comunicação e sociabilidade da Compós e aos pareceristas e editores da revista E-Compós. 


\section{Luz del Fuego: celebrity, gender and morality in Brazil}

\begin{abstract}
In this article, we analyze the fame of Luz del Fuego in Brazilian magazines and newspapers between 1930 and 1970. Four outstanding themes were identified in the material: carnival, violence, censorship and politics. The research analyzes the relationship between celebrity, gender and culture, observing the ways in which Luz del Fuego was positioned as a famous woman. The work indicates that Luz del Fuego knew how to be a succès de scandale, having planned a career, first and foremost, in media. The conclusions indicate that, by promoting moral disturbances in the public space, she participated ambiguously in the transformations of the social roles of women and men between 1950 and 1970.
\end{abstract}

\section{Keywords}

Celebrity. Gender and media. Media history.

\section{Luz del Fuego: celebridad, género y moralidad en Brasil}

\section{Resumen}

Este artículo presenta la trayectoria mediática de Luz del Fuego en revistas y periódicos brasileños de 1930 a 1970. Se han identificado cuatro temas: carnaval, violencia, censura y política. La investigación examina, en torno a estos temas, la relación entre celebridades, género y cultura, observando las formas en que Luz del Fuego se ha posicionado como una mujer famosa. Luz del Fuego sabía ser un éxito de escándalo, y planeó una carrera, en primer lugar, en los medios. Los resultados muestran que al promover disturbios morales en el espacio público, ella participó ambiguamente en las transformaciones de los roles sociales de mujeres y hombres entre 1950 y 1970.

\section{Palabras clave}

Celebridad. Género y medios. Historia de los medios.

\section{Everardo Rocha}

Doutor em Antropologia Social pelo Museu Nacional da Universidade Federal do Rio de Janeiro. Professor Titular do Departamento de Comunicação Social e do Programa de Pós-Graduação em Comunicação da PUC-Rio. Bolsista de Produtividade em Pesquisa do CNPq. Bolsista do Programa Cientista do Nosso Estado da Fundação Carlos Chagas Filho de Amparo à Pesquisa do Estado do Rio de Janeiro. Coordenador do Laboratório de Antropologia do Consumo: Comunicação, Tempo Presente e História Cultural - LAC do Programa de Pós-Graduação em Comunicação da PUC-Rio.

Pontifícia Universidade Católica do Rio de Janeiro, Rio de Janeiro, Brasil

E-mail: everardo@puc-rio.br

ORCID: https://orcid.org/0000-0001-5821-1917

\section{Lígia Lana}

Doutora em Comunicação pelo Programa de PósGraduação em Comunicação da Universidade Federal de Minas Gerais com estágio sanduíche junto à École des Hautes Études en Sciences Sociales (2009-2010/CNPq). Pós-Doutorado Júnior (PDJ/CNPq) junto à Escola de Comunicação da Universidade Federal do Rio de Janeiro, entre 2012 e 2014. Pesquisadora de pós-doutorado (PAPDRJ/Capes-Faperj) no Programa de Pós-Graduação em Comunicação Social da PUC-Rio.

Pontifícia Universidade Católica do Rio de Janeiro, Rio de Janeiro, Brasil

E-mail: ligialana@gmail.com

ORCID: https://orcid.org/0000-0002-2397-1008

\section{Contribuição dos autores}

Concepção e desenho do estudo:

Everardo Rocha; Lígia Lana

Aquisição, análise ou interpretação dos dados:

Everardo Rocha; Lígia Lana

Redação do manuscrito: Lígia Lana

Revisão crítica do conteúdo intelectual: Everardo Rocha 